\title{
Automatic Irrigation System using WSN Technology
}

\author{
${ }^{1}$ Mridula Jopat, ${ }^{2}$ Pratiksha Lonkar \\ ${ }^{1,2}$ Student, St. John College of Engineering \& Management in Mumbai (India). \\ 1.jopatmridula@gmail.com, ${ }^{2}$ pratikshalonkar32@gmail.com
}

\begin{abstract}
Agriculture in India contributes maximum for GDP growth. Various parameters impact the proper cultivation of crop. Agriculture requires $90 \%$ of water resources. Automated Irrigation System is developed to utilize the available resources in most efficient manner. Threshold value of Temperature \& Humidity sensor are used to control the quantity of water. WSN technology has been used to provide updates of farm conditions to the farmer. Automation in the field of farming brings the biggest revolution in our country. The available resources will be utilized in most appropriate manner. The Automation will lead to high yield of crops by utilizing the resources in efficient way. The farm conditions can be displayed to farmer using Graphical representation method
\end{abstract}

Keywords - Temperature \& Humidity Sensor, Wireless Sensor Network, Zigbee.

\section{INTRODUCTION}

Wireless Sensor Network Technology contains distributed network of various sensing nodes where each node communicating with other spatially distributed nodes and the central unit [2]. Sensor node contains few sensors and radio module along with a smart device. Various signal information from the sensors are gathered in Arduino and transmitted to the Irrigation Control Centre (ICC) via Zigbee [1]. Based on the threshold values programmed in Arduino, the water motor will be turned ON/OFF. System becomes more user friendly by use of GUI. The additional facility to turn the motor ON/ OFF remotely makes it much useful for the farmer.

\section{MOTIVATION}

The main occupation in India is Agriculture which contributes to maximum economy growth. The available water resources have to be utilized in proper way to achieve sustainable development. There has been reduction in rainfall from past few years, which lead to scarify land reservoir water availability. The main goal is to achieve more yield with proper utilization of available resources. Sometimes manual intervention leads to wastage of water. The automatic irrigation system provide the better way to reduce human work along with adequate usage of water. The irrigation system can be deployed for variety of crop needs by adjusting the threshold values of sensors. The smart configuration of automatic irrigation system also requires less maintenance with minimal human intervention.

\section{NEED OF PROJECT}

Agriculture is the main occupation of India which supports economic growth of our country. So there urges the need to bring innovation in field of farming. Hence we developed the system which utilizes the available resources in efficient way \& also reduce the manual effort. Various parameters of farm can also be monitored remotely.

\section{METHADOLOGY}

\section{A. System Overview}

The Figure I shows the overall implementation of designed system.

The system consists of ZigBee as coordinator, router and end devices [3]. The data collected via various sensors are transmitted from end devices to coordinator via router. The data is represented via GUI (Central Unit). It helps to remotely monitor most of the farm conditions.

The entire system consist of two unit: 1) WSU- Wireless Sensor Unit 2) WIU - Wireless Information Unit.

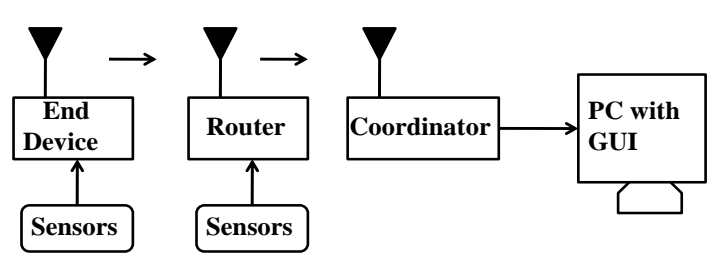

Fig. 1: Design Overview

\section{B. Hardware and Software Requirement}

1. MATLAB and Arduino IDE installed on PC

2. Arduino UNO (Atmega 328p)

3. ZigBee module (Xbee pro S2B)

4. Temperature and Humidity Sensor (DHT11)

4. Soil Moisture Sensor

6. Water Motor 
7. X-CTU software installed on PC/Laptop

Wireless Sensor Unit: WSU consist of RF transceiver, microcontroller, Sensors, and power supply. WSU communicates with WIU [4]. Various sensors sense the data which is then stored in microcontroller. WSU are deployed in farms at spatial different locations. The WIU unit is placed at farmers home. Farmer can remotely monitor the farm conditions using GUI. The farmer also have the remote access to turn the water motor ON/OFF as per his/her choice. The diagrammatic representation of WSU \& WIU is shown below.

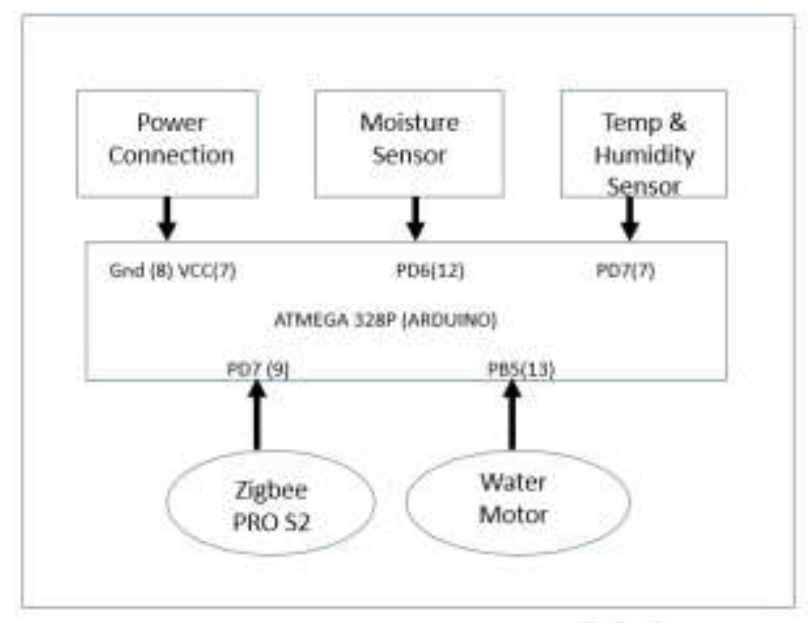

Fig. 2: Wireless Sensor Unit (WSU)

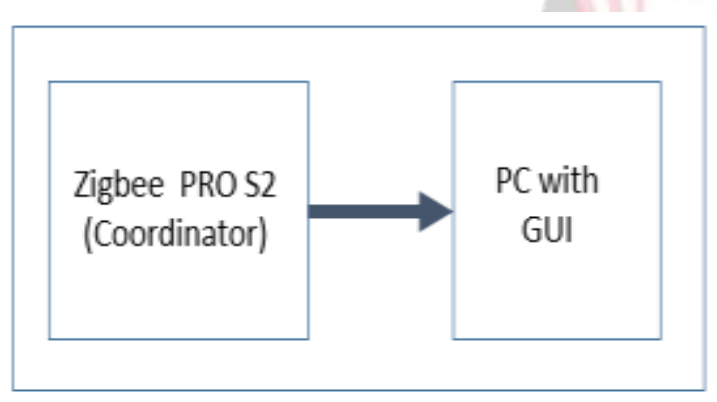

Fig. 3 : Wireless Information Unit (WIU)

Wireless Information Unit: This unit is made up of PC and Zigbee as coordinator. Temperature \& Humidity contents of soil is received via Router \& displayed using GUI to the farmer.

\section{Principle of Operation}

1) WSU Unit Working: The proposed Prototype consist of two WSU units deployed at farm. Each WSU unit consist of Temperature \& Humidity sensor, moisture sensor, microcontroller \& Zigbee configured as end device used to transmit the information in wireless mode Programming in sensors is done using Embedded $\mathrm{C}$ in Arduino UNO.

2) Proposed GUI: MATLAB software is used to develop the GUI shown below. Two buttons named as Node1 and Node2 are used to collect various soil parameters like temperature and humidity from respective node. There has been a provision provided in GUI to control the motor remotely. Automatic control of water motor is based on the threshold value of moisture programmed in the sensors.

3) WIU Unit Working: The WIU unit is placed at Farmer's home premises. WIU unit is made up of Zigbee as Coordinator, microcontroller \& PC with GUI display [6]. The sensed information about farms conditions reaches to coordinator via Router $\&$ is graphically displayed on screen of computer.

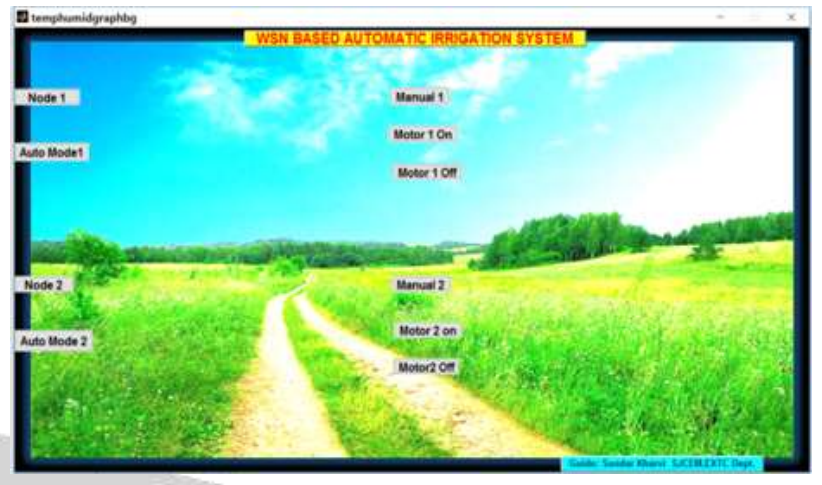

Fig. 4: Proposed GUI in MATLAB

\section{SYSTEM FLOWCHART}

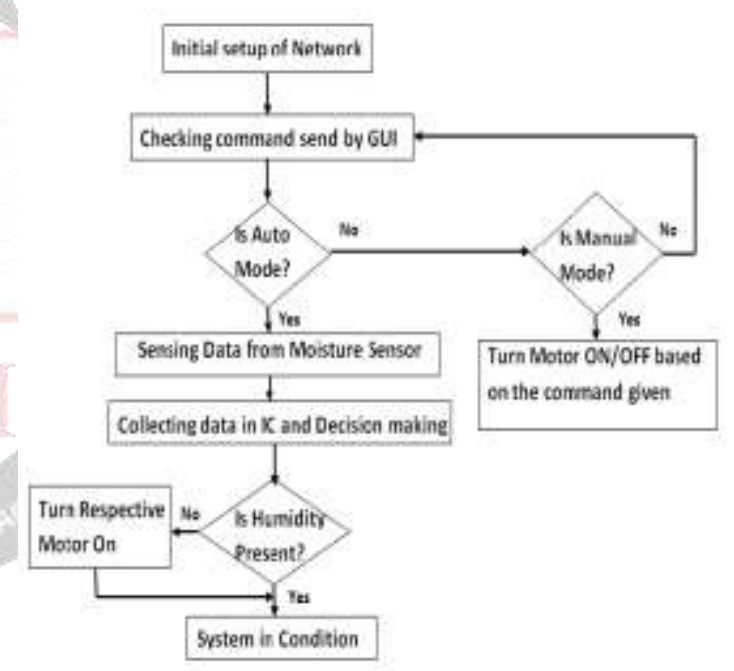

Fig. 5: System Flowchart

The flowchart depicts the working of entire system .It shows the flow of data been collected at sensors at WSU unit \& transmitted remotely via router to coordinator \& displaying the same information to farmer using GUI [7].The nodes are deployed in farm at various location. The farmer can send out the command using Zigbee (Coordinator) to various nodes. Based on these commands the temperature \& humidity conditions are displayed to farmer on GUI. There is two provision provided to farmer for motor. Based on the threshold values the motor can be turned ON/OFF automatically. Secondly based on farmer decision he can also turn the motor ON/OFF. 


\section{RESUlTS}

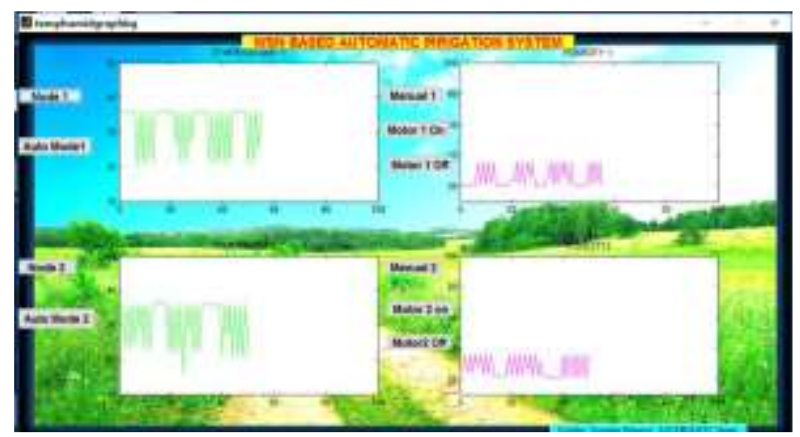

Fig. 6 : Graph of temarature and humidity in GUI

Fig.6 displays the real time reading of temparature and humidity information collected from two different nodes. As two different nodes have been deployed, data from these nodes are collected \& represnted in graphical form to the farmer [8].There is a provision provided to the farmer to turn the Motor ON/OFF as per his desire. So by clicking on Motor ON button he can turn the Motor on for the corresponding farm \& vice versa.

\section{FUTURE WORK}

The power supply is the major drawback of this prototype. DC power suppled via battery is not the ideal case as it would not be useful if the farm size is huge. The battery power supply is not useful in the practical implementation. Lithium ion battery is too costly and charging is a problem. The solution is to power the entire system using solar supply. So the power supply changes will be made in the upcoming project to make it more efficient in terms of power consumption.

\section{CONCLUSION}

The designed system consists of star topology of sensor nodes which communicates with central information unit. The Central Information Unit is deployed at farms House from where he can monitor the farm condition. The sensing units are deployed in farm at various location. This paper presents design and implementation of WSN technology that helps in remotely monitoring of various parameters such as temperature, humidity and moisture in a crop field and controlling the motore remotely. This helps us to reduce the manual intervention with motive of sustainable development. The proper utilization of available water resources can be done by adopting this method. The farmer can have updates about his Farm condition by monitoring them on GUI.

\section{REFERENCES}

[1] Shuangde Zhang,'Design and implementation of flowers watering control system based on the zigbee', Journal of Chemical and Pharmaceutical Research, 2014, 6(1).
[2] Vadlamudi Madhan Kumar,Suganthi Brindha G; International Journal of Science, Engineering and Technology Research (IJSETR) Volume 4, Issue 4, April 2015 "Monitoring Of Green House Gases Using Wireless Sensor Networks with Arduino Board"

[3] Shahini Pathan, Ms. S. G. Hate, 'Automated Irrigation System using wireless Sensor Network', International Journal of Engineering Research \& Technology (IJERT), Vol-5, Issue-06 June 2016.

[4] V.Swami, A.Krishnamurthy; International Journal of Modern Engineering Research (IJMER) www.ijmer.com Vol. 3, Issue. 5, Sep - Oct. 2013 pp2853-2856 ISSN: 2249- 6645; "Remote Monitoring of crop field using wireless sensor network.

[5] N. Mohan Krishna, Prof. G. V. Marutheswar, 'Automatic Irrigation System Monitoring by using GPRS or ZIGBEE', International Journal of Engineering Research \& Technology (IJERT), Vol. 5 Issue 01 , January-2016

[6] V.Swami, A.Krishnamurthy; International Journal of Modern Engineering Research (IJMER) www.ijmer.com Vol. 3, Issue. 5, Sep - Oct. 2013 pp2853-2856 ISSN: 2249- 6645; "Remote Monitoring of crop field using wireless sensor network

[7] Carlos F. García-Hernández, Pablo H. Ibargüengoytia González, Joaquín García-Hernández, and Jesús A. Pérez-Díaz, 'Wireless Sensor Networks and Applications: a Survey', (IJCSNS) International Journal of Computer Science and Network Security, VOL.7 No.3, March 2007.

[8] Janani P, Dr. N SaravanKumar 'Automatic Filed Irrigation Setup using MATLAB', International Journal of Advanced Research in Electronics \& Communication Engineering, VOL.5, Issue 2, February 2016. 